\title{
Pharmacokinetics and pharmacogenetics of Gemcitabine as a mainstay in adult and pediatric oncology: an EORTC-PAMM perspective
}

\author{
Joseph Ciccolini $^{1} \cdot$ Cindy Serdjebi $^{1} \cdot$ Godefridus J. Peters $^{2} \cdot$ Elisa Giovannetti $^{2,3}$
}

Received: 15 July 2015 / Accepted: 8 February 2016 / Published online: 23 March 2016

(C) The Author(s) 2016. This article is published with open access at Springerlink.com

\begin{abstract}
Gemcitabine is an antimetabolite ranking among the most prescribed anticancer drugs worldwide. This nucleoside analog exerts its antiproliferative action after tumoral conversion into active triphosphorylated nucleotides interfering with DNA synthesis and targeting ribonucleotide reductase. Gemcitabine is a mainstay for treating pancreatic and lung cancers, alone or in combination with several cytotoxic drugs (nab-paclitaxel, cisplatin and oxaliplatin), and is an option in a variety of other solid or hematological cancers. Several determinants of response have been identified with gemcitabine, i.e., membrane transporters, activating and inactivating enzymes at the tumor level, or Hedgehog signaling pathway. More recent studies have investigated how germinal genetic polymorphisms affecting cytidine deaminase, the enzyme responsible for the liver disposition of gemcitabine, could act as well as a marker for clinical outcome (i.e., toxicity, efficacy) at the bedside. Besides, constant efforts have been made to develop alternative chemical derivatives or encapsulated forms of gemcitabine, as an attempt to improve its metabolism and pharmacokinetics profile. Overall, gemcitabine is a drug paradigmatic for constant searches of the scientific community to improve its administration through the development of personalized medicine in oncology.
\end{abstract}

Elisa Giovannetti

elisa.giovannetti@gmail.com

1 Pharmacokinetics Unit, SMARTc, Inserm S_911 CRO2, Aix Marseille University, Marseille, France

2 Department of Medical Oncology, VUmc, Amsterdam, The Netherlands

3 Cancer Pharmacology Lab, AIRC/Start-Up Unit, University of Pisa, Pisa, Italy
Keywords Gemcitabine $\cdot 2^{\prime}, 2^{\prime}$-difluoro-2'-deoxyuridine . Cytidine deaminase $\cdot$ Polymorphisms $\cdot$ Pharmacogenetics . Gemcitabine prodrugs

\section{Introduction}

Among the pyrimidine analogs, gemcitabine $\left(2^{\prime}, 2^{\prime}\right.$-difluorodeoxycytidine, dFdC; Gemzar $\left.{ }^{\circledR}\right)$ is one the most widely used drugs in clinical oncology and ranked the third anticancer agent prescribed worldwide. It is a cytidine analog, where two fluorine atoms have replaced the hydroxyl on the ribose. In particular, gemcitabine is a mainstay in pancreatic adenocarcinoma $[1,2]$ and is widely prescribed to treat a variety of other solid tumors such as breast, ovarian, bladder or non-small-cell lung (NSCLC) cancers [3, 4]. In addition to solid tumors, gemcitabine is indicated as well in several hematological disorders such as acute leukemia [5]. Beyond adult patients, gemcitabine can be an attractive option in pediatric cancers because its toxic profile is usually considered as mild as compared with other cytotoxic drugs.

After administration and taken up by the cancer cell, gemcitabine undergoes an initial phosphorylation by deoxycytidine kinase (dCK) and to a lower extent by the extramitochondrial thymidine kinase 2 , followed by a series of phosphorylation steps in order to be incorporated into both DNA and RNA as its active phosphorylated form gemcitabine triphosphate (dFdCTP) [6]. Additionally, gemcitabine diphosphate (dFdCDP) inhibits ribonucleotide reductase (RR), an enzyme in the nucleotide pathway critical for the cancer cell to manage its pools of deoxynucleotides. The clearance of gemcitabine is mostly driven by rapid and extensive inactivation by cytidine deaminase (CDA) to its primary metabolite $2^{\prime}, 2^{\prime}$-difluoro-deoxyuridine $(\mathrm{dFdU})$; 

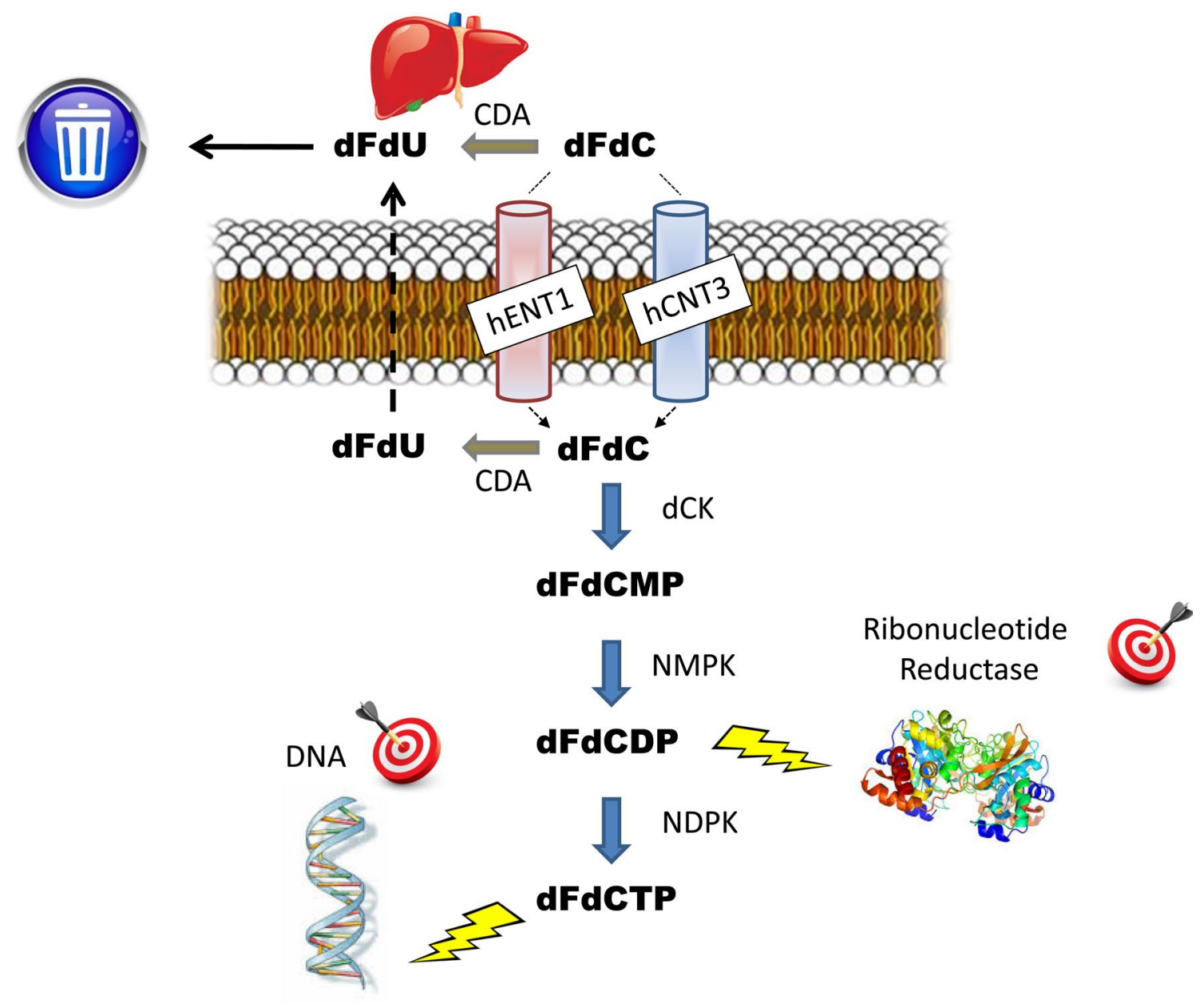

Fig. 1 Gemcitabine $(\mathrm{dFdC})$ patterns and mechanisms of action. $C D A$ cytidine deaminase, $d C K$ deoxycytidine kinase, $N M P K$ nucleotide monophosphate kinase, NDPK nucleotide diphosphate kinase, $h E N T 1$ human equilibrative nucleoside transporter-1, hCNT3 human con-

CDA is expressed ubiquitously at high levels in both plasma and the liver, [7]. A 24-h hepatic artery infusion of gemcitabine to the liver underlined the important role for liver CDA-mediated catabolism to $\mathrm{dFdU}$, since the Cmax and area-under-curve of $\mathrm{dFdU}$ were similar for the hepatic artery infusion and a 24-h intravenous infusion of gemcitabine, while gemcitabine plasma levels were much lower after the hepatic artery infusion [8]. Figure 1 briefly summarizes these main steps of gemcitabine metabolism and mechanisms of action.

Because gemcitabine is the backbone of numerous regimens, several studies have tried to identify molecular or genetic determinants of response, both at the somatic and the constitutional levels [9]. In addition, recent efforts have been made to improve the metabolism and pharmacokinetics (DM-PK) profile of gemcitabine, creating novel chemical derivatives, prodrugs or nanomedicine forms [10]. centrative nucleoside transporter-3. In cancer cells, genetic polymorphisms affecting membrane transporters, activating and deactivating enzymes and pharmacological targets such as ribonucleotide reductase, are all associated with treatment efficacy

\section{Gemcitabine pharmacokinetics and pharmacodynamics}

Because of its hydrophilic nature, gemcitabine does not readily cross the membrane by diffusion, and it is transported into the cells by membrane nucleoside transporters [11]. Following cellular uptake, gemcitabine is phosphorylated to its active diphosphate ( $\mathrm{AFdCDP}$ ) and triphosphate (dFdCTP) metabolites, which inhibit RR and DNA synthesis, respectively [12]. $\mathrm{dCK}$ is the rate-limiting enzyme in the biotransformation of nucleoside analogs, and several studies have suggested that $\mathrm{dCK}$ is a limiting factor for gemcitabine activity, because its deficiency/modulation is critically involved in acquired resistance in different in vitro models [13, 14]. Moreover, pretreatment dCK expression level could be used as a predictive parameter of tumor sensitivity, as observed with a clear correlation 
between dCK activity and gemcitabine sensitivity in tumor cells and xenografts [15].

The dynamics of dFdCDP and dFdCTP formation and activity in vivo are complex; $\mathrm{dFdCTP}$ is incorporated into DNA followed by one or more deoxynucleotides masking gemcitabine and preventing DNA repair by $3^{\prime} 5^{\prime}$-exonuclease activity, a process designated as "masked DNA chain termination" [16]. This causes an S-phase-specific cell cycle arrest and programmed cell death. dFdCTP is also incorporated into RNA, thus inhibiting RNA synthesis [17], while dFdCDP inhibits RR, inducing a depletion of the cellular pool of deoxynucleoside triphosphates, and blocks the de novo DNA synthesis pathway [18].

However, only a proportion of gemcitabine is converted into the active di- or triphosphate forms. The majority of gemcitabine is rapidly inactivated in the liver and to a lesser extent in blood by deamination into dFdU, through a reaction catalyzed by CDA. Additionally, $10 \%$ of unchanged gemcitabine can undergo renal filtration, and within 1 week, more than $90 \%$ of the injected dose is usually recovered in the urine, either as parent gemcitabine (1\%) or dFdU (99\%) [19]. In addition, the formation of dFdCTP and dFdCDP from dFdCMP is reduced through deamination of dFdCMP to $2^{\prime}, 2^{\prime}$-difluorodeoxyuridine monophosphate (dFdUMP) by dCMP deaminase. Notably, an elevated concentration of dFdCTP inhibits dCMP deaminase, determining a "self-potentiation" of the drug activity [20], which is also caused by the increase in dFdCTP accumulation induced by $\mathrm{dFdU}$ in a time-dependent manner [21]. dFdCTP also inhibits CTP synthetase, affecting RNA synthesis by depletion of CTP, while the latter decreases dCTP synthesis [22, 23]. Finally, a recent study demonstrated that gemcitabine can inhibit the enzyme thymidylate synthase presumably through the phosphorylated metabolite dFdUMP. Inhibition of this enzyme enhances the mis-incorporation of $2^{\prime}$-deoxyuridine into DNA, causing indirect damage [24].

A considerable inter-patient variability has been described in gemcitabine accumulation, and the pharmacokinetics of gemcitabine and its main metabolite $\mathrm{dFdU}$ in plasma have been evaluated in multiple studies. Gemcitabine plasma concentrations generally reach a plateau after 15-30 min during the standard 30 min infusion protocol. Linear pharmacokinetics have been described over the range $40-3650 \mathrm{mg} / \mathrm{m}^{2}$, and nonlinear pharmacokinetics at higher doses [19, 25, 26]. Mean gemcitabine peak plasma concentrations ranged from $24 \mu \mathrm{M}$ at $800 \mathrm{mg} / \mathrm{m}^{2}$ [27] to $32 \mu \mathrm{M}$ at $1000 \mathrm{mg} / \mathrm{m}^{2}$ [28], around $53-70 \mu \mathrm{M}$ at a dose of $1250 \mathrm{mg} / \mathrm{m}^{2}$ [29, 30], $68-79 \mu \mathrm{M}$ at $2350 \mathrm{mg} / \mathrm{m}^{2}$ and between 320 and $512 \mu \mathrm{M}$ at the MTD of $5700 \mathrm{mg} / \mathrm{m}^{2}$ [19]. Up to at least at gemcitabine $1250 \mathrm{mg} / \mathrm{m}^{2}$, deamination was linear with mean plasma $\mathrm{dFdU}$ concentrations being 1.25 times higher as compared to $\mathrm{dFdU}$ levels using gemcitabine
$1000 \mathrm{mg} / \mathrm{m}^{2}$. Linearity was lost at doses higher than $3650 \mathrm{mg} / \mathrm{m}^{2}$ [19]. The clearance of gemcitabine in the plasma is also rapid (i.e., T1/2 of 5-20 min). More than $75 \%$ of gemcitabine is metabolised to $\mathrm{dFdU}$ and excreted in the urine in the first $24 \mathrm{~h}$ [19]. This clearance is independent of dose over the linear range (i.e., up to $3650 \mathrm{mg} /$ $\mathrm{m}^{2}$ ), but proportional to creatinine clearance. At the highest doses, the clearance was lower; moreover, the clearance was 1.5 -fold higher in men $\left(8.61 / \mathrm{m}^{2}\right)$ compared to women $\left(5.7 \mathrm{l} / \mathrm{m}^{2}\right)$ [19]. The pharmacokinetic elimination half-life for $\mathrm{dFdU}$ varies between 2 and $24 \mathrm{~h}$, and it is still present systemically in concentrations greater than $1 \mu \mathrm{M}$ up to 1 week after dosing [31]. Of note, since dFdU is not protein bound, its plasma concentration, up to $460 \mu \mathrm{M}$ [19], depending on the dose administered, is freely available. These concentrations are cytotoxic [20,32] and could have significant implications in the clinical use of gemcitabine alone or in combination with other therapies, such as radiation [33], since dFdU has a radiosensitizing effect by itself.

Since gemcitabine is often given in combination with other cytotoxic and targeted drugs, the effect of combination therapy on the pharmacokinetics has been investigated in several clinical studies, since theoretically co-medication can affect both drug metabolism and elimination. However, in the most widely used combination with cisplatin or paclitaxel, no evidence was found for an effect of these drugs (as well as oxaliplatin and carboplatin) on both gemcitabine and $\mathrm{dFdU}$ pharmacokinetics, investigated within the same patients and between patients $[27,28,30,34$, 35]. Similarly, the proteasome inhibitor bortezomib and the farnesyltransferase inhibitor SCH66336 did not affect the pharmacokinetics of gemcitabine or $\mathrm{dFdU}$, alone or in the combination with cisplatin [36, 37]. Moreover, no effect of the VEGFR inhibitor SU5416 was observed [29], while the EGFR inhibitor gefitinib tended to increase the exposure to gemcitabine [38]. However, the other EGFR inhibitor erlotinib did not affect pharmacokinetics of the gemcitabine prodrug LY2334737 itself or of gemcitabine and dFdU [39]. Hence, from the point of view of pharmacokinetics, it can be concluded that in general gemcitabine can safely be combined with other drugs, both other cytotoxics and novel targeted drugs. Naturally, this does not exclude that gemcitabine affects the mechanism of action of other drugs or that these other drugs affect intracellular metabolism of gemcitabine. Two examples include the potentiation by gemcitabine of cisplatin adduct formation and the selective effect of bortezomib on intracellular gemcitabine activation $[27,40]$.

Less data are available on the pharmacokinetics of dFdCTP, which should be measured with more sensitive LCMS assays [41]. However, several studies demonstrated that cells exposed to gemcitabine have saturable accumulation of the dFdCTP, and the optimal plasma concentration 
of gemcitabine that maximized the rate of formation of dFdCTP was approximately $20 \mu \mathrm{mol} / 1[42,43]$. This is accompanied by a change in the pattern of elimination with monophasic elimination at low concentrations and biphasic elimination described after the threshold has been reached.

Since the optimal intracellular accumulation of $\mathrm{dFdCTP}$ was achieved with dose rates of $10 \mathrm{mg} / \mathrm{m}^{2} / \mathrm{min}[25,43]$, a number of phase I trials have explored the possibility to prolong the duration of infusion time, while other trials escalated both the dose and infusion duration [25, 44, 45]. The rationale for prolonged dosing received a major boost when a randomised phase II trial in a clinically relevant scenario (pancreatic cancer) demonstrated that prolonged infusion at a rate of $10 \mathrm{mg} / \mathrm{m}^{2} / \mathrm{min}$, compared to the standard dosing regimen with $30 \mathrm{~min}$ infusion, was associated with increased accumulation of dFdCTP, as well as with a significant increase in response rate and a trend for increased survival [46]. Similar trials in different tumor types confirmed the pharmacokinetic finding, but were underpowered to demonstrate survival differences [47]. Unfortunately, a large phase III study in pancreatic cancer showed that the pharmacological advantage failed to translate into a significant survival advantage [34].

Collectively, these clinical studies indicate that the antitumor effect of gemcitabine is schedule dependent and that lower doses can be efficacious. Therefore, it could be advantageous to deliver gemcitabine in a manner where it can achieve prolonged systemic exposure, good efficacy with lower toxicity along with added flexibility of administration and greater patient convenience, such as using an oral formulation [48]. However, administering gemcitabine orally to patients has been limited by low oral bioavailability, high first-pass clearance, variable systemic exposures during dose escalation studies and observation of gastrointestinal toxicity including nausea, vomiting and diarrhea.

\section{Dysregulation at the germinal level: pharmacogenetics of gemcitabine}

Factors extracted from either clinical or pathological data such as age, performance status, comorbidity and disease stage or grade provide a crude discrimination of prognosis, but are often not predictive and not helpful for the choice of the best chemotherapeutic regimen for a given patient. Novel approaches to stratify patient's prognosis or toxicity may be offered by pharmacogenetic analyses of selected candidate polymorphisms that could influence the expression of genes involved in drug metabolic pathways.

Historically, pharmacogenetics is indeed defined as the study of germline mutations (e.g., single-nucleotide polymorphisms affecting genes coding for enzymes responsible for drug pharmacokinetics), whereas pharmacogenomics refers to the role of both acquired and inherited genetic differences in relation to drug behavior through a systematic examination of genes, gene products and inter- and intra-individual variation in gene expression and function using new genomic technologies [49]. However, in oncology, pharmacogenetics is often considered as concerning the individual patient's features and pharmacogenomics as those of the tumor.

\section{CDA deregulations and clinical outcome}

Gemcitabine is primarily detoxified in the liver by CDA into $\mathrm{dFdU}$, with a $\mathrm{Km}$ of approximatively $96 \mu \mathrm{M}[50,51]$. Usually, $90 \%$ of gemcitabine is detoxified by CDA, and variations in enzymatic activity impact greatly on drug pharmacokinetics and pharmacodynamics. Mice with impaired CDA displayed sharp overexposure to the drug with subsequent unrecoverable hematological toxicities [52], thus highlighting the correlation between CDA deficiency, overexposure to gemcitabine and increased risk of severe toxicities. Indeed, a variety of studies and case reports have found a correlation between CDA deficiency syndrome and an increase in severe hematological toxicities in patients undergoing gemcitabine-based therapy [52, 53]. Of note, the first-ever reported case of toxic death related to CDA deficiency in an ovarian cancer patient treated with the gemcitabine-carboplatin was published in 2007 [53]. Profound functional deficiency was retrospectively evidenced, with heterozygous $\mathrm{CDA} * 2$ genotype. Subsequent genetic investigations revealed a new intronic mutation (i.e., $154+37 \mathrm{G}>\mathrm{A}$ ) on the $\mathrm{CDA}$ gene, likely to have caused the lethal toxicities [54]. Of note, other studies have shown that patients with lower CDA activity also tend to display higher response rates and better survival $[55,56]$. On the contrary, it has been observed that about $15 \%$ of the Caucasian adult population display CDA activities significantly higher than the median values of adult populations (i.e., over $6 \mathrm{U} / \mathrm{mg}$ ), making them prone to therapeutic failure because most of standard dosing of gemcitabine will be metabolized in the liver before it even reaches the tumor tissues [52]. A pilot study involving 40 patients treated by gemcitabine-based regimens for pancreatic cancer confirmed that patients displaying CDA ultrametabolizer phenotype were fivefold more at risk to have a progressive disease than patients with normal CDA status [57]. As expected, these patients had milder toxicities than patients with normal or lower CDA activity, an observation completely in line with previous reports about CDA and gemcitabine-related toxicities. Overall, all these studies, conducted by independent groups and involving patients treated with gemcitabine used alone or in a combination for a variety of settings, demonstrate how CDA status greatly 
affects clinical outcome in patients undergoing gemcitabine-based treatments.

\section{CDA genetic polymorphisms}

CDA is coded by the 4-exons gene CDA located on the first pair of chromosomes (1p36.2-p35). CDA is formed by four identical subunits, all presenting a zinc atom in the active site. It is mostly expressed in liver and placenta, but high levels of CDA are also expressed in mature neutrophils and erythrocytes [58]. CDA is responsible for the physiological deamination of cytidine and 2'-deoxycytidine into uridine and 2 -deoxyuridine, respectively. Because a wide interpatient variability has been observed with CDA, numerous studies have been undertaken to screen for possible mutations and polymorphisms affecting the CDA gene since the mid-70s, both in germinal cells and in cancer cells [59-62]. As of today, up to 1000 genetic variations affecting CDA have been described. The most studied polymorphisms are the two non-synonymous $79 \mathrm{~A}>\mathrm{C}(\mathrm{rs} 2072671)$ and $208 \mathrm{G}>\mathrm{A}$ (rs60369023) substitutions and the synonymous $435 \mathrm{C}>\mathrm{T}$ (rs1048977) variant [63-66]. Beside these polymorphisms affecting coding regions, many other mutations of the promoter region such as the -31 delC deletion (rs3215400) or $-92 \mathrm{~A}>\mathrm{G}$ (rs602950), or in intronic regions such as the $154+37 \mathrm{G}>\mathrm{A}$ polymorphism (rs12059454) have been described [54, 67-70]. All these genetic variations lead to inconsistent and sometimes conflictual results in term of resulting phenotypic status $[69,70]$, as reported in the Table 1.

Indeed, the large inter-individual variability reported with CDA activity is only partly explained by the genetic background. In addition, because more than 1000 genetic variations have been evidenced, SNP-candidate studies are probably underpowered strategies, yielding conflictual data $[51,55,64,68,71,72]$. For instance, the 79A $>C$ polymorphism (i.e., $\mathrm{CDA} * 2$ ) leads to lysine to glutamine permutation in position 27 , with no impact on the catalytic site eventually, but other factors might play a role. Of note, ethnicity plays a crucial role in the allelic frequencies of this variant because minor allele frequency (MAF) ranges from $10 \%$ in African population, $15 \%$ in Asian population, but up to $35 \%$ in Caucasians [73, 74]. The phenotypic impact of this allelic variant and its consequence in the clinical outcome in patients treated with nucleoside analogs remain controversial: a decrease in CDA activity has been measured for the Lys ${ }^{27}$ Lys variant $[75,76]$, whereas other studies suggest no variation $[52,77]$ or lower activity for the $\operatorname{Gln}^{27} \mathrm{Gln}$ variant $[78,79]$. These differences may be partly explained by variations in study design such as patient selection, ethnicity and treatment regimens [80-82]. A pivotal study has recently been published, collecting data about CDA catalytic activity according to substrates, both

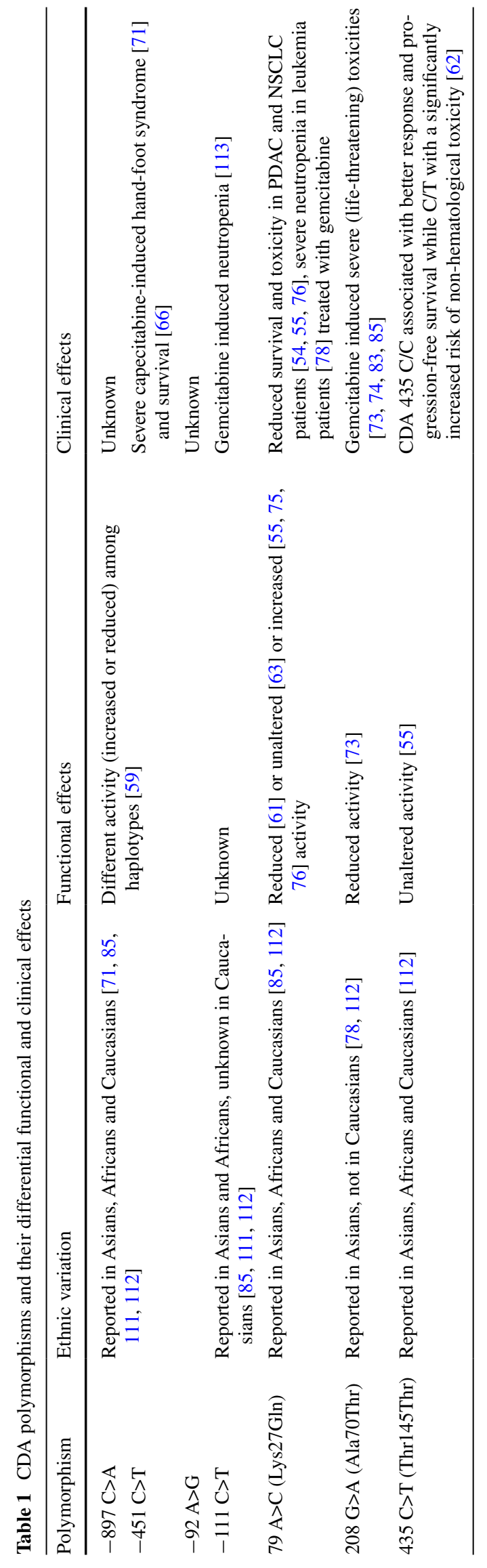


natural and synthetic [83]. This biochemical study, inspired from a previous work in 2012 by Baker and collaborators [79], highlights that catalytic efficiency of CDA enzyme is dependent on the genetic sequence encoding for the protein, but also on the drugs used as substrates. Surprisingly, an increase in CDA catalytic efficiency was observed for the $\mathrm{CDA}^{27} \mathrm{Gln}$ protein with natural cytidine analogs and cytarabine, but surprisingly a decrease was found for other substrates such as 5-azacytidine, 6-azacytidine and fazarabine. This is in agreement with the results of the study by Giovannetti et al. [75], in which $\mathrm{CDA}^{27} \mathrm{Gln}$ activity was investigated with gemcitabine, with a decrease in deaminase activity being observed with this polymorphism.

In addition to the $C D A * 2$ allelic variant, another polymorphism has been studied extensively: CDA*3, resulting from the substitution of alanine to threonine in position 70 because of the 208G $>$ A SNP in the coding sequence. With the $\mathrm{CDA}^{*} 3$ variant, impact on CDA phenotype is more univocal because researchers all agree that a decrease in CDA activity is found for the protein encoded by $208 \mathrm{~A} / \mathrm{A}$ variant $[68,74,83]$. Indeed, deaminase activity was found to be 100-fold lower than normal CDA with respect to all tested drugs with this allelic variant [57]. Of note and unlike $\mathrm{CDA} * 2$, which is found in every population, but in different proportions, $\mathrm{CDA} * 3$ has never been detected in Caucasian populations, but is only found in Africans and Asians. To date, the clinical impact of $\mathrm{CDA} * 3$ genotype in patients treated with gemcitabine has been repeatedly reported in Japanese patients only [74, 83, 84]. In addition, two studies have aimed at establishing the respective MAF of $79 \mathrm{~A}>\mathrm{C}$, $208 \mathrm{G}>\mathrm{A}$ and $435 \mathrm{C}>\mathrm{T}$ in both Asian and Caucasian populations $[67,85]$. Few differences were observed in MAF of $435 \mathrm{C}>\mathrm{T}$ allelic variant when comparing these two ethnicities, whereas discrepancies were evidenced for the 79A $>\mathrm{C}$ and $208 \mathrm{G}>\mathrm{A}$ variants. For the $\mathrm{CDA} * 2$ allelic variant, twice as many individuals carry a wild-type genotype with a lower incidence of $\mathrm{C} / \mathrm{C}$ genotype in Asians, as compared with white people. The discrepancy is more marked for the rs60369023 variant because no individual, whether in African-Americans, Chinese-Americans, or Caucasian-Americans, was carrying the minor allele A. Only 11 patients were heterozygous among over 400 Korean and Japanese patients, and none of them was found to be homozygous for the $\mathrm{CDA}^{*} 3$ variant [85]. These data confirm that screening for $208 \mathrm{G}>\mathrm{A}$ single-nucleotide polymorphism has a clinical, yet limited, meaning in Asian or more significantly in Japanese populations only. As mentioned above, numerous other genetic variations have been identified, but no study has established a clear link between a given genotype and the resulting phenotype yet, apart for the -31 delC variant (rs532545), a CDA promoter deletion possibly resulting in an amplification of the CDA gene with functional (i.e., ultrametabolizer phenotype) impact eventually [71]. These data call for more sophisticated multigenic or haplotypebased studies to establish a clear genotype-to-phenotype relationship with CDA and gemcitabine.

\section{Dysregulation at the tumor level: pharmacogenomics of gemcitabine}

Several determinants for efficacy have been identified with gemcitabine at the tumor level. Because gemcitabine requires facilitated transport for cellular uptake [11], several studies evaluated the expression levels of the plasma membrane human equilibrative nucleoside transporter-1 (hENT1) and human concentrative nucleoside transporter-3 (hCNT3), showing their prognostic and predictive roles of drug activity in patients undergoing gemcitabine-based regimen [86-89]. Higher uptake in cancer cells with high levels of both transporters could explain the marked increase in disease-free survival and overall survival observed in pancreatic cancer patients administered with gemcitabine. Of note, several polymorphisms affecting the genes coding for hENT1 and hCNT3 have been described. These polymorphisms might impact protein expression, but the functional and clinical significance of these polymorphisms have yet to be defined [10].

Other determinants for response at the tumor level include the expression of $\mathrm{dCK}$, the rate-limiting enzyme activating the prodrug gemcitabine to active nucleotides [90], deoxycytidylate deaminase that metabolizes active phosphorylated nucleotides into inactive metabolites [6] and RR that is one of the gemcitabine targets [91]. These genes have many polymorphisms, which could impact on drug efficacy, but the relevance of all these markers has not been fully confirmed at the bedside. Large prospective control studies are necessary to confirm the role of these determinants in response to gemcitabine.

However, the candidate-gene approach used in most of these studies cannot establish if a positive association is due to linkage with untyped functional variant alleles or due to intragene interaction. Drug efficacy and toxicity may also be influenced by other genes and pathways, which will be undetected by single-polymorphism analysis. Therefore, alternative approaches through the broader application of new genomic technologies might be necessary to identify novels biomarkers of gemcitabine efficacy and toxicity, and to bring us closer to tailor-made therapy for individual patients [92]. Li et al. [93] used such a method to identify novel genes involved in gemcitabine metabolism. After analyzing data with 26,653 probe sets, the researchers identified 15 genes where mRNA expression correlated with cytidine analog sensitivity and, from there, selected FKBP5 for further functional variation. FKBP5 is a gene involved in steroid receptor mutation and is a binding partner for 
rapamycin, suggesting that it may have a role in the apoptosis pathway. Overexpression of FKBP5 correlated with increased gemcitabine chemosensitivity. Using FKBP5 siRNA-treated cells, the researchers showed a decrease in downstream enzyme caspase-3/7 activity, confirming that the activation of the apoptotic pathway was affected by the downregulation of FKBP5 expression.

Recently, it has also been shown that tumor blood perfusion and vessels' density could be associated with response to drug-based therapy, probably in relation with a drug delivery issue. In this respect, the Hedgehog signaling pathway has been suggested as being a new determinant of response with gemcitabine, since it is associated with production of a desmoplastic tumor stroma and a reduced tumoral perfusion eventually, probably through the expression of Gli family transcriptor factors. As a result, Hedgehog signaling could prevent at least partly gemcitabine to be delivered to tumors $[94,95]$. This rising concern in both experimental and clinical oncology about the role Hedgehog protein plays, highlights the fact that beyond pharmacological molecular determinants, the issue of drug delivery becomes more and more critical $[96,97]$. This issue is currently addressed by recent efforts to develop "gemcitabine 2.0." forms likely to display improved distribution and cellular uptake profiles.

\section{Gemcitabine prodrugs}

In order to overcome various forms of drug resistance and/ or to improve drug delivery, recent studies evaluated several gemcitabine prodrugs. Since many clinical studies showed that a low expression of hENT1 was associated with a poor survival of pancreatic cancer patients receiving gemcitabine [97-99], Clavis Pharma developed an elaidic acid prodrug modified at the $5^{\prime}$-sugar position, CP-4126, which was able to bypass hENT1. CP-4126 was similarly effective as gemcitabine in various model systems in vivo and showed an oral efficacy, possibly because CP-4126 could also inhibit CDA, preventing or reducing its firstpass effect [98]. Because of its efficacy in phase II studies, CP-4126 (as CO-101) was tested in a phase II randomized, multicenter trial in comparison with gemcitabine as first-line therapy in metastatic pancreatic cancer patients [99]. Mandatory tumor biopsy specimens were evaluated for their hENT1 expression in both treatment groups. The similar effect of CO-101 and gemcitabine demonstrated an effective conversion of the prodrug to gemcitabine. However, the study did not reach its anticipated endpoint, an increased efficacy of CO-101 compared to gemcitabine in the low hENT1 group of patients. Of note, no difference in survival was found also between the low and high hENT group treated with gemcitabine, suggesting that the role of hENT1 is less important in metastatic disease than after surgery, as shown in the patients in the earlier adjuvant studies. However, it is also possible that the lack of difference between the patients with low and high hENT1 expression was due to a lower specificity of the antibody, which was different from that used in earlier studies.

Another gemcitabine prodrug currently in clinical development is LY2334737, which has valproic acid attached to the N4 of the base. Valproic acid is cleaved off by carboxylesterase 2 (CES2), which is high in the liver and gastrointestinal tract, resulting in an early cleavage of the molecule, as well as in a better antitumor activity in tumors with a high CES2 activity. A phase I dose-finding study with oral administration (daily for 14 days, with 1 week rest) showed linear pharmacokinetics, until the maximal tolerated dose of $40 \mathrm{mg}$ in Caucasian and $30 \mathrm{mg}$ in Japanese patients, with a lower toxicity profile compared to oral gemcitabine [39, 100]. However, using other schedules (every other day for 21 days followed by 1 week rest, or daily for 7 days every other week), the maximal tolerated dose was $90 \mathrm{mg} / \mathrm{m}^{2}$, which was recommended for phase II studies for the every other day schedule [101].

Nucana developed another type of prodrug, NUC-1031, which is a gemcitabine analog to which a phosphoramidate ProTide moiety has been added. This novel nucleotide evades all three main cellular resistance mechanisms associated with gemcitabine (i.e., nucleoside transport, dCKmediated activation and CDA-mediated degradation). NUC1031 showed activity in cell culture and in in vivo models, including xenografts resistant to systemic gemcitabine treatment, while dFdCTP reaching tenfold higher levels in white blood cells than was found for gemcitabine at similar doses [102, 103]. More recently, NUC-1031 showed clear signs of clinical activity in patients with gynecological cancers. This agent was well tolerated, and a phase Ib study of NUC-1031 in combination with carboplatin is ongoing, while phase III studies are planned in both platinum sensitive and refractory gynecological cancers [104].

Another approach to increase delivery consists in the use nanoparticles that can be designed to allow controlled/ sustained drug release [105]. These systems are more stable than liposomes, but retain their low immunogenicity. Gemcitabine-loaded gold nanoparticles targeted to the epidermal growth factor receptor with cetuximab had an increased targeting and activity of gemcitabine in pancreatic tumors in vitro and in mouse tumor models [106]. Similarly, gemcitabine covalently coupled with the natural lipid 1,1',2-tris-nor-squalenic acid (squalene) at its 4-amino moiety, resulting in 4-(N)-tris-nor-squalenoyl-gemcitabine, which spontaneously assemble into a hexagonal structure with an aqueous core, was active in both human and murine leukemia resistant cell lines and tumors [107]. 
Gemcitabine can also be covalently coupled via polyethylene glycol (PEG) to another molecule that can target the complex to tumor cells, such as for PEG-gemcitabine conjugates to folic acid, binding specifically to the folate receptors, which are highly overexpressed on the surface of many cancers [108]. Finally, gemcitabine can also be loaded in PEGylated liposomes [109].

\section{Conclusions and perspectives}

There are few drugs in oncology that are as old, but still so widely used as chemotherapeutic targets such as gemcitabine. Gemcitabine is indeed approved and commonly used, alone or in combination, for the treatment of several tumor types, such as NSCLC, pancreatic, bladder, ovarian and breast cancer. In order to improve its antitumor activity while reducing toxic effects, many studies investigated pharmacokinetics [110] and/or the impact of genetic polymorphisms and CDA activity [51, 55], as well as tumorspecific expression of hENT1 mRNA and protein [87, 88], on gemcitabine toxicity and efficacy. These factors appear to be the most promising predictive indicators of outcome in patients receiving gemcitabine chemotherapy $[9,10]$.

However, most pharmacogenetic studies were retrospective and monocentric, without multiple correction and validation in broader populations. Most phenotypic studies used different methods and specimens; for example, a number of assays have been used to determine CDA activity in various blood compartments [111]. Moreover, most clinical trials on gemcitabine combinations were performed without previous preclinical studies evaluating molecular mechanisms and markers of drug synergistic interaction, while pharmacogenomics studies on tumor specimens did not evaluate tumor heterogeneity and possible evolution of cancer cells after tumor relapse, which should be faithfully documented within multiple samples of the single tumor as well as repeated biopsies.

Therefore, future efforts should be redirected at identifying, both in preclinical models and in the clinical setting, either sensitive or non-responding genotypes or phenotypes. These profiles should be identified with validated methods, which should be used for the appropriate patient enrollment into subsequent prospective studies.

Hopefully, in the near future, the availability of validated genetic/phenotypic platforms will lead to the selection of key factors responsible of the chemosensitivity and toxicity to gemcitabine-based treatments and guide in the choice of more effective rationally based tailor-made treatments for each patient.

Acknowledgments This work was supported by grants from Cancer Center Amsterdam (CCA) Foundation (to GJP and EG), Istituto
Toscano Tumori (ITT) and Associazione Italiana per la Ricerca sul Cancro (AIRC) (to EG).

\section{Compliance with ethical standards}

Conflict of interest Joseph Ciccolini owns a patent on CDA testing (US 20130011392 A1).

Open Access This article is distributed under the terms of the Creative Commons Attribution 4.0 International License (http://creativecommons.org/licenses/by/4.0/), which permits unrestricted use, distribution, and reproduction in any medium, provided you give appropriate credit to the original author(s) and the source, provide a link to the Creative Commons license, and indicate if changes were made.

\section{References}

1. Burris HA 3rd, Moore MJ, Andersen J, Green MR, Rothenberg ML, Modiano MR, Cripps MC, Portenoy RK, Storniolo AM, Tarassoff P, Nelson R, Dorr FA, Stephens CD, Von Hoff DD (1997) Improvements in survival and clinical benefit with gemcitabine as first-line therapy for patients with advanced pancreas cancer: a randomized trial. J Clin Oncol 15:2403-2413

2. Sandler A, Ettinger DS (1999) Gemcitabine: single-agent and combination therapy in non-small cell lung cancer. Oncologist $4: 241-251$

3. Shelley MD, Jones G, Cleves A, Jones G, Cleves A, Wilt TJ, Mason MD, Kynaston HG (2012) Intravesical gemcitabine therapy for non-muscle invasive bladder cancer (NMIBC): a systematic review. BJU Int 109:496-505

4. Kroep JR, Giaccone G, Tolis C, Voorn DA, Loves WJ, Groeningen CJ, Pinedo HM, Peters GJ (2000) Sequence dependent effect of paclitaxel on gemcitabine metabolism in relation to cell cycle and cytotoxicity in non-small-cell lung cancer cell lines. Br J Cancer 83:1069-1076

5. Kim TM, Kim S, Ahn YO, Lee SH, Kim DW, Heo DS (2014) Anti-cancer activity of gemcitabine against natural killer cell leukemia/lymphoma. Leuk Lymphoma 55:940-943

6. Mini E, Nobili S, Caciagli B, Landini I, Mazzei T (2006) Cellular pharmacology of gemcitabine. Ann Oncol 17(Suppl 5):v7-v12

7. Serdjebi C, Milano G, Ciccolini J (2015) Role of cytidine deaminase in toxicity and efficacy of nucleosidic analogs. Expert Opin Drug Metab Toxicol 11:665-672. doi:10.1517/17 425255.2015.985648

8. van Riel JM, Peters GJ, Mammatas LH, Honeywell RJ, Laan AC, Ruyter R, van den Berg FG, Giaccone G, van Groeningen CJ (2009) A phase I and pharmacokinetic study of gemcitabine given by 24-h hepatic arterial infusion. Eur J Cancer 45:25192527. doi:10.1016/j.ejca.2009.05.025

9. Ciccolini J, Mercier C, Dahan L, André N (2011) Integrating pharmacogenetics into gemcitabine dosing-time for a change? Nat Rev Clin Oncol 8:439-444. doi:10.1038/nrclinonc.2011.1

10. Elnaggar M, Giovannetti E, Peters GJ (2012) Molecular targets of gemcitabine action: rationale for development of novel drugs and drug combinations. Curr Pharm Des 18:2811-2829

11. Mackey JR, Mani RS, Selner M, Mowles D, Young JD, Belt JA, Crawford CR, Cass CE (1998) Functional nucleoside transporters are required for gemcitabine influx and manifestation of toxicity in cancer cell lines. Cancer Res 58:4349-4357

12. Peters GJ, van der Wilt CL, van Moorsel CJ, Kroep JR, Bergman AM, Ackland SP (2000) Basis for effective combination 
cancer chemotherapy with antimetabolites. Pharmacol Ther $87: 227-253$

13. van Bree C, Castro Kreder N, Loves WJ, Franken NA, Peters GJ, Haveman J (2002) Sensitivity to ionizing radiation and chemotherapeutic agents in gemcitabine-resistant human tumor cell lines. Int J Radiat Oncol Biol Phys 54:237-244

14. Giovannetti E, Mey V, Nannizzi S, Pasqualetti G, Marini L, Del Tacca M, Danesi R (2005) Cellular and pharmacogenetics foundation of synergistic interaction of pemetrexed and gemcitabine in human non-small-cell lung cancer cells. Mol Pharmacol 68:110-118

15. Kroep JR, Loves WJ, van der Wilt CL, Alvarez E, Talianidis I, Boven E, Braakhuis BJ, van Groeningen CJ, Pinedo HM, Peters GJ (2002) Pretreatment deoxycytidine kinase levels predict in vivo gemcitabine sensitivity. Mol Cancer Ther 1:371-376

16. Huang P, Chubb S, Hertel LW, Grindey GB, Plunkett W (1991) Action of $2^{\prime}, 2^{\prime}$-difluorodeoxycytidine on DNA synthesis. Cancer Res 51:6110-6117

17. Ruiz van Haperen V, Veerman G, Vermorken JB, Peters GJ (1993) 2',2'-Difluoro-deoxycytidine (gemcitabine) incorporation into RNA and DNA of tumour cell lines. Biochem Pharmacol 46:762-766

18. Heinemann V, Xu YZ, Chubb S, Sen A, Hertel LW, Grindey GB, Plunkett W (1990) Inhibition of ribonucleotide reduction in CCRF-CEM cells by $2^{\prime}, 2^{\prime}$-difluorodeoxycytidine. Mol Pharmacol 38:567-572

19. Peters GJ, Clavel M, Noordhuis P, Geyssen GJ, Laan AC, Guastalla J, Edzes HT, Vermorken JB (2007) Clinical phase I and pharmacology study of gemcitabine $\left(2^{\prime}, 2^{\prime}\right.$-difluorodeoxycytidine) administered in a two-weekly schedule. J Chemother 19:212-221

20. Heinemann V, Xu YZ, Chubb S, Sen A, Hertel LW, Grindey GB, Plunkett W (1992) Cellular elimination of $2^{\prime}, 2^{\prime}$ - difluorodeoxycytidine 5'-triphosphate: a mechanism of self-potentiation. Cancer Res 52:533-539

21. Hodge LS, Taub ME, Tracy TS (2011) The deaminated metabolite of gemcitabine, $2^{\prime}, 2^{\prime}$-difluorodeoxyuridine, modulates the rate of gemcitabine transport and intracellular phosphorylation via deoxycytidine kinase. Drug Metab Dispos 39:2013-2016. doi:10.1124/dmd.111.040790

22. Heinemann V, Schulz L, Issels RD, Plunkett W (1995) Gemcitabine: a modulator of intracellular nucleotide and deoxynucleotide metabolism. Semin Oncol 22(4 Suppl 11):11-18

23. Van Moorsel CJA, Bergman AM, Veerman G, Voorn DA, Ruiz van Haperen VWT, Kroep JR, Pinedo HM, Peters GJ (2000) Differential effects of gemcitabine on ribonucleotide pools of twenty-one solid tumour and leukemia cell lines. Biochim Biophys Acta 1474:5-12

24. Honeywell RJ, Ruiz van Haperen VW, Veerman G, Smid K, Peters GJ (2015) Inhibition of thymidylate synthase by $2^{\prime}, 2^{\prime}$-difluoro- $2^{\prime}$-deoxycytidine (Gemcitabine) and its metabolite $2^{\prime}, 2^{\prime}$-difluoro-2'-deoxyuridine. Int $\mathrm{J}$ Biochem Cell Biol 60:73-81. doi:10.1016/j.biocel.2014.12.010

25. Abbruzzese JL, Grunewald R, Weeks EA, Gravel D, Adams T, Nowak B, Mineishi S, Tarassoff P, Satterlee W, Raber MN (1991) A phase I clinical, plasma, and cellular pharmacology study of gemcitabine. J Clin Oncol 9:491-498

26. Peters GJ, Schornagel JH, Milano GA (1993) Clinical pharmacokinetics of anti-metabolites. Cancer Surv 17:123-156

27. van Moorsel CJ, Kroep JR, Pinedo HM, Veerman G, Voorn DA, Postmus PE, Vermorken JB, van Groeningen CJ, van der Vijgh WJ, Peters GJ (1999) Pharmacokinetic schedule finding study of the combination of gemcitabine and cisplatin in patients with solid tumors. Ann Oncol 10:441-448

28. Kroep JR, Giaccone G, Voorn DA, Smit EF, Beijnen JH, Rosing $\mathrm{H}$, van Moorsel CJ, van Groeningen CJ, Postmus PE, Pinedo
HM, Peters GJ (1999) Gemcitabine and paclitaxel: pharmacokinetic and pharmacodynamic inter- actions in patients with nonsmall-cell lung cancer. J Clin Oncol 17:2190-2197

29. Kuenen BC, Rosen L, Smit EF, Parson MR, Levi M, Ruijter R, Huisman H, Kedde MA, Noordhuis P, van der Vijgh WJ, Peters GJ, Cropp GF, Scigalla P, Hoekman K, Pinedo HM, Giaccone G (2002) Dose-finding and pharmacokinetic study of cisplatin, gemcitabine, and SU5416 in patients with solid tumors. J Clin Oncol 20:1657-1667

30. Kroep JR, Smit EF, Giaccone G, Van der Born K, Beijnen JH, Van Groeningen CJ, Van der Vijgh WJ, Postmus PE, Pinedo HM, Peters GJ (2006) Pharmacology of the paclitaxel-cisplatin, gemcitabine-cisplatin, and paclitaxel-gemcitabine combinations in patients with advanced non-small cell lung cancer. Cancer Chemother Pharmacol 58:509-516

31. de Lange SM, van der Born K, Kroep JR, Jensen HA, Pfeiffer P, Cleverly A, van Groeningen CJ, Peters GJ (2005) No evidence of gemcitabine accumulation during weekly administration. Eur J Clin Pharmacol 61:843-849

32. Ruiz van Haperen VW, Veerman G, Boven E, Noordhuis P, Vermorken JB, Peters GJ (1994) Schedule dependence of sensitivity to $2^{\prime}, 2^{\prime}$-difluorodeoxycytidine (Gemcitabine) in relation to accumulation and retention of its triphosphate in solid tumour cell lines and solid tumours. Biochem Pharmacol 48:1327-1339

33. Pauwels B, Korst AE, Lambrechts HA, Pattyn GG, de Pooter CM, Lardon F, Vermorken JB (2006) The radiosensitising effect of difluorodeoxyuridine, a metabolite of gemcitabine, in vitro. Cancer Chemother Pharmacol 58:219-228

34. Poplin E, Feng Y, Berlin J, Rothenberg ML, Hochster H, Mitchell E, Alberts S, O'Dwyer P, Haller D, Catalano P, Cella D, Benson AB 3rd (2009) Phase III, randomized study of gemcitabine and oxaliplatin versus gemcitabine (fixed-dose rate infusion) compared with gemcitabine (30-minute infusion) in patients with pancreatic carcinoma E6201: a trial of the Eastern Cooperative Oncology Group. J Clin Oncol 27:3778-3785. doi:10.1200/JCO.2008.20.9007

35. Faivre S, Le Chevalier T, Monnerat C, Lokiec F, Novello S, Taieb J, Pautier P, Lhommé C, Ruffié P, Kayitalire L, Armand JP, Raymond E (2002) Phase I-II and pharmacokinetic study of gemcitabine combined with oxaliplatin in patients with advanced non-small-cell lung cancer and ovarian carcinoma. Ann Oncol 13:1479-1489

36. Voortman J, Smit EF, Honeywell R, Kuenen BC, Peters GJ, Van de Velde H, Giaccone G (2007) A parallel dose-escalation study of weekly and twice-weekly bortezomib in combination with gemcitabine and cisplatin in the first-line treatment of patients with advanced solid tumors. Clin Cancer Res 13:3642-3651

37. Theodore C, Geoffrois L, Vermorken JB, Caponigro F, Fiedler W, Chollet P, Ravaud A, Peters GJ, Balincourt C, Fumoleau P (2005) Multicentre EORTC study 16997: feasibility and phase II trial of farnesyl transferase inhibitor and gemcitabine combination in salvage treatment of advanced urothelial tract cancers. Eur J Cancer 41:1150-1157

38. Giaccone G, González-Larriba JL, Van Oosterom AT, Alfonso R, Smit EF, Martens M, Peters GJ, Van der Vijgh WJF, Smith R, Averbuch S, Fandi A (2004) Combination therapy with gefitinib, an epidermal growth factor receptor tyrosine kinase inhibitor, gemcitabine and cisplatin in patients with advanced solid tumors. Ann Oncol 15:831-838

39. Koolen SL, Witteveen PO, Jansen RS, Langenberg MH, Kronemeijer RH, Nol A, Garcia-Ribas I, Callies S, Benhadji KA, Slapak CA, Beijnen JH, Voest EE, Schellens JH (2011) Phase I study of Oral gemcitabine prodrug (LY2334737) alone and in combination with erlotinib in patients with advanced solid tumors. Clin Cancer Res 17:6071-6082 
40. Ceresa C, Giovannetti E, Voortman J, Laan AC, Honeywell R, Giaccone G, Peters GJ (2009) Bortezomib induces schedule-dependent modulation of gemcitabine pharmacokinetics and pharmacodynamics in non-small cell lung cancer and blood mononuclear cells. Mol Cancer Ther 8:1026-1036. doi:10.1158/1535-7163.MCT-08-0700

41. Honeywell RJ, Giovannetti E, Peters GJ (2011) Determination of the phosphorylated metabolites of gemcitabine and of difluorodeoxyuridine by LCMSMS. Nucleosides Nucleotides Nucleic Acids 30:1203-1213

42. Grunewald R, Kantarjian H, Keating MJ, Abbruzzese J, Tarassoff P, Plunkett W (1990) Pharmacologically directed design of the dose rate and schedule of $2^{\prime}, 2^{\prime}$-difluorodeoxycytidine (Gemcitabine) administration in leukemia. Cancer Res 50:6823-6826

43. Grunewald R, Abbruzzese JL, Tarassoff P, Plunkett W (1991) Saturation of $2^{\prime}, 2^{\prime}$-difluorodeoxycytidine $5^{\prime}$-triphosphate accumulation by mononuclear cells during a phase I trial of gemcitabine. Cancer Chemother Pharmacol 27:258-262

44. Grunewald R, Kantarjian H, Du M, Faucher K, Tarassoff P, Plunkett W (1992) Gemcitabine in leukemia: a phase I clinical, plasma, and cellular pharmacology study. J Clin Oncol 10:406-413

45. Pollera CF, Ceribelli A, Crecco M, Oliva C, Calabresi F (1997) Prolonged infusion gemcitabine: a clinical phase I study at low- $\left(300 \mathrm{mg} / \mathrm{m}^{2}\right)$ and high-dose $\left(875 \mathrm{mg} / \mathrm{m}^{2}\right)$ levels. Invest New Drugs 15:115-121

46. Tempero M, Plunkett W, Ruiz Van Haperen V, Hainsworth J, Hochster H, Lenzi R, Abbruzzese J (2003) Randomized phase II comparison of dose-intense gemcitabine: thirty-minute infusion and fixed dose rate infusion in patients with pancreatic adenocarcinoma. J Clin Oncol 21:3402-3408

47. Bengala C, Guarneri V, Giovannetti E, Lencioni M, Fontana E, Mey V, Fontana A, Boggi U, Del Chiaro M, Danesi R, Ricci S, Mosca F, Del Tacca M, Conte PF (2005) Prolonged fixed dose rate infusion of gemcitabine with autologous haemopoietic support in advanced pancreatic adenocarcinoma. Br J Cancer 93:35-40

48. Wickremsinhe E, Bao J, Smith R, Burton R, Dow S, Perkins E (2013) Preclinical absorption, distribution, metabolism, and excretion of an oral amide prodrug of gemcitabine designed to deliver prolonged systemic exposure. Pharmaceutics 5:261276. doi:10.3390/pharmaceutics5020261

49. Robert J, Le Morvan V, Giovannetti E, Peters GJ, PAMM Group of EORTC (2014) On the use of pharmacogenetics in cancer treatment and clinical trials. Eur J Cancer 50:2532-2543. doi:10.1016/j.ejca.2014.07.013

50. Cattel L, Airoldi M, Delprino L, Passera R, Milla P, Pedani F (2006) Pharmacokinetic evaluation of gemcitabine and $2^{\prime}, 2^{\prime}$-difluorodeoxycytidine-5'-triphosphate after prolonged infusion in patients affected by different solid tumors. Ann Oncol 17(Suppl 5):v142-v147

51. Ciccolini J, Dahan L, André N, Evrard A, Duluc M, Blesius A, Yang C, Giacometti S, Brunet C, Raynal C, Ortiz A, Frances N, Iliadis A, Duffaud F, Seitz JF, Mercier C (2010) Cytidine deaminase residual activity in serum is a predictive marker of early severe toxicities in adults after gemcitabine-based chemotherapies. J Clin Oncol 28:160-165

52. Mercier C, Raynal C, Dahan L, Ortiz A, Evrard A, Dupuis C, Blesius A, Duluc M, Franceschini F, Giacometti S, Salas S, Milano G, Favre R, Seitz JF, Ciccolini J (2007) Toxic death case in a patient undergoing gemcitabine-based chemotherapy in relation with cytidine deaminase downregulation. Pharmacogenet Genomics 17:841-844

53. Raynal C, Ciccolini J, Mercier C, Boyer JC, Polge A, Lallemant B, Mouzat K, Lumbroso S, Brouillet JP, Evrard A (2010) High-resolution melting analysis of sequence variations in the cytidine deaminase gene (CDA) in patients with cancer treated with gemcitabine. Ther Drug Monit 32:53-56

54. Farrell JJ, Bae K, Wong J, Guha C, Dicker AP, Elsaleh H (2012) Cytidine deaminase single-nucleotide polymorphism is predictive of toxicity from gemcitabine in patients with pancreatic cancer: rTOG 9704. Pharmacogenomics J 12:395-403

55. Tibaldi C, Giovannetti E, Tiseo M, Leon LG, D'Incecco A, Loosekoot N, Bartolotti M, Honeywell R, Cappuzzo F, Ardizzoni A, Peters GJ (2012) Correlation of cytidine deaminase polymorphisms and activity with clinical outcome in gemcitabine-/ platinum-treated advanced non-small-cell lung cancer patients. Ann Oncol 23:670-677

56. Serdjebi C, Seitz JF, Ciccolini J, Duluc M, Norguet E, Fina F, Lacarelle B, Ouafik L, Dahan L (2013) Rapid deaminator status is associated with poor clinical outcome in pancreatic cancer patients treated with a gemcitabine-based regimen. Pharmacogenomics 14:1047-1051

57. Micozzi D, Carpi FM, Pucciarelli S, Polzonetti V, Polidori P, Vilar S, Williams B, Costanzi S, Vincenzetti S (2014) Human cytidine deaminase: a biochemical characterization of its naturally occurring variants. Int J Biol Macromol 63:64-74

58. Schroder JK, Kirch C, Seeber S, Schutte J (1998) Structural and functional analysis of the cytidine deaminase gene in patients with acute myeloid leukaemia. Br J Haematol 103:1096-1103

59. Fitzgerald SM, Goyal RK, Osborne WR, Roy JD, Wilson JW, Ferrell RE (2006) Identification of functional single nucleotide polymorphism haplotypes in the cytidine deaminase promoter. Hum Genet 119:276-283

60. Teng YS, Anderson JE, Giblett ER (1975) Cytidine deaminase: a new genetic polymorphism demonstrated in human granulocytes. Am J Hum Genet 27:492-497

61. Gilbert JA, Salavaggione OE, Ji Y, Pelleymounter LL, Eckloff BW, Wieben ED, Ames MM, Weinshilboum RM (2006) Gemcitabine pharmacogenomics: cytidine deaminase and deoxycytidylate deaminase gene resequencing and functional genomics. Clin Cancer Res 12:1794-1803

62. Ludovini V, Floriani I, Pistola L, Minotti V, Meacci M, Chiari R, Garavaglia D, Tofanetti FR, Flacco A, Siggillino A, Baldelli E, Tonato M, Crinò L (2011) Association of cytidine deaminase and xeroderma pigmentosum group D polymorphisms with response, toxicity, and survival in cisplatin/gemcitabine-treated advanced non-small cell lung cancer patients. J Thorac Oncol 6:2018-2026

63. Maring JG, Wachters FM, Slijfer M, Maurer JM, Boezen HM, Uges DR, de Vries EG, Groen HJ (2010) Pharmacokinetics of gemcitabine in non-small-cell lung cancer patients: impact of the 79A $>$ C cytidine deaminase polymorphism. Eur J Clin Pharmacol 66:611-617

64. Mercier C, Dupuis C, Blesius A, Fanciullino R, Yang CG, Padovani L, Giacometti S, Frances N, Iliadis A, Duffaud F, Ciccolini J (2009) Early severe toxicities after capecitabine intake: possible implication of a cytidine deaminase extensive metabolizer profile. Cancer Chemother Pharmacol 63:1177-1780

65. Parmar S, Seeringer A, Denich D, Gärtner F, Pitterle K, Syrovets T, Ohmle B, Stingl JC (2011) Variability in transport and biotransformation of cytarabine is associated with its toxicity in peripheral blood mononuclear cells. Pharmacogenomics 12:503-514

66. Mahlknecht U, Dransfeld CL, Bulut N, Kramer M, Thiede C, Ehninger G, Schaich M (2009) SNP analyses in cytarabine metabolizing enzymes in AML patients and their impact on treatment response and patient survival: identification of CDA SNP C-451T as an independent prognostic parameter for survival. Leukemia 23:1929-1932

67. Soo RA, Wang LZ, Ng SS, Chong PY, Yong WP, Lee SC, Liu JJ, Choo TB, Tham LS, Lee HS, Goh BC, Soong R (2009) 
Distribution of gemcitabine pathway genotypes in ethnic Asians and their association with outcome in non-small cell lung cancer patients. Lung Cancer 63:121-127

68. Sugiyama E, Kaniwa N, Kim SR, Kikura-Hanajiri R, Hasegawa R, Maekawa K, Saito Y, Ozawa S, Sawada J, Kamatani N, Furuse J, Ishii H, Yoshida T, Ueno H, Okusaka T, Saijo N (2007) Pharmacokinetics of gemcitabine in Japanese cancer patients: the impact of a cytidine deaminase polymorphism. J Clin Oncol 25:32-42

69. Mercier C, Evrard A, Ciccolini J (2007) Genotype-based methods for anticipating gemcitabine-related severe toxicities may lead to false-negative results. J Clin Oncol 25:4855; author reply 4855-6

70. Giovannetti E, Tibaldi C, Falcone A, Danesi R, Peters GJ (2010) Impact of cytidine deaminase polymorphisms on toxicity after gemcitabine: the question is still ongoing. J Clin Oncol 28:e221-e222

71. Caronia D, Martin M, Sastre J, de la Torre J, García-Sáenz JA, Alonso MR, Moreno LT, Pita G, Díaz-Rubio E, Benítez J, González-Neira A (2011) A polymorphism in the cytidine deaminase promoter predicts severe capecitabine-induced handfoot syndrome. Clin Cancer Res 17:2006-2013

72. Serdjebi C, Ciccolini J, Fina F, Delarue A, Verschuur A, Lacarelle B, Ouafik L, André N (2014) Recipient/donor contradictory genotypes with impact on drug pharmacogenetics after liver transplant: a deadly gift? Pharmacogenet Genomics 24:527-529

73. Yue L, Saikawa Y, Ota K, Tanaka M, Nishimura R, Uehara T, Maeba H, Ito T, Sasaki T, Koizumi S (2003) A functional single-nucleotide polymorphism in the human cytidine deaminase gene contributing to ara-C sensitivity. Pharmacogenetics $13: 29-38$

74. Ueno H, Kaniwa N, Okusaka T, Ikeda M, Morizane C, Kondo S, Sugiyama E, Kim SR, Hasegawa R, Saito Y, Yoshida T, Saijo N, Sawada J (2009) Homozygous CDA*3 is a major cause of life-threatening toxicities in gemcitabine-treated Japanese cancer patients. Br J Cancer 100:870-873

75. Giovannetti E, Laan AC, Vasile E, Tibaldi C, Nannizzi S, Ricciardi S, Falcone A, Danesi R, Peters GJ (2008) Correlation between cytidine deaminase genotype and gemcitabine deamination in blood samples. Nucleosides Nucleotides Nucleic Acids 27:720-725

76. Tibaldi C, Giovannetti E, Vasile E, Mey V, Laan AC, Nannizzi S, Di Marsico R, Antonuzzo A, Orlandini C, Ricciardi S, Del Tacca M, Peters GJ, Falcone A, Danesi R (2008) Correlation of CDA, ERCC1, and XPD polymorphisms with response and survival in gemcitabine/cisplatin-treated advanced non-small cell lung cancer patients. Clin Cancer Res 14:1797-1803

77. Abraham A, Varatharajan S, Abbas S, Zhang W, Shaji RV, Ahmed R, Abraham A, George B, Srivastava A, Chandy M, Mathews V, Balasubramanian P (2012) Cytidine deaminase genetic variants influence RNA expression and cytarabine cytotoxicity in acute myeloid leukemia. Pharmacogenomics $13: 269-282$

78. Xu J, Zhou Y, Zhang J, Chen Y, Zhuang R, Liu T, Cai W (2012) High incidence of severe neutropenia after gemcitabine-based chemotherapy in Chinese cancer patients with CDA 79A $>\mathrm{C}$ mutation. Clin Chim Acta 413:1284-1287

79. Baker JA, Wickremsinhe ER, Li CH, Oluyedun OA, Dantzig AH, Hall SD, Qian YW, Ring BJ, Wrighton SA, Guo Y (2013) Pharmacogenomics of gemcitabine metabolism: functional analysis of genetic variants in cytidine deaminase and deoxycytidine kinase. Drug Metab Dispos 41:541-545

80. Mahfouz RZ, Jankowska A, Ebrahem Q, Gu X, Visconte V, Tabarroki A, Terse P, Covey J, Chan K, Ling Y, Engelke KJ, Sekeres MA, Tiu R, Maciejewski J, Radivoyevitch T,
Saunthararajah Y (2013) Increased CDA expression/activity in males contributes to decreased cytidine analogue half-life and likely contributes to worse outcomes with 5-azacytidine or decitabine therapy. Clin Cancer Res 19:938-948

81. Ciccolini J, Peters GJ, Giovannetti E (2013) Gender, cytidine deaminase, and 5-aza/decitabine-letter. Clin Cancer Res 19:3105. doi:10.1158/1078-0432.CCR-13-0483

82. Grepin R, Guyot M, Jacquin M, Durivault J, Chamorey E, Sudaka A, Serdjebi C, Lacarelle B, Scoazec JY, Negrier S, Simonnet H, Pages G (2012) Acceleration of clear cell renal cell carcinoma growth in mice following bevacizumab/Avastin treatment: the role of CXCL cytokines. Oncogene 31:1683-1694

83. Yonemori K, Ueno H, Okusaka T, Yamamoto N, Ikeda M, Saijo N, Yoshida T, Ishii H, Furuse J, Sugiyama E, Kim SR, KikuraHanajiri R, Hasegawa R, Saito Y, Ozawa S, Kaniwa N, Sawada J (2005) Severe drug toxicity associated with a single-nucleotide polymorphism of the cytidine deaminase gene in a Japanese cancer patient treated with gemcitabine plus cisplatin. Clin Cancer Res 11:2620-2624

84. Ciccolini J, Evrard A, Lacarelle B (2012) A CDD polymorphism as predictor of capecitabine-induced hand-foot syndrome-letter. Clin Cancer Res 18:317

85. Sugiyama E, Lee SJ, Lee SS, Kim WY, Kim SR, Tohkin M, Hasegawa R, Okuda H, Kawamoto M, Kamatani N, Sawada J, Kaniwa N, Saito Y, Shin JG (2009) Ethnic differences of two non-synonymous single nucleotide polymorphisms in CDA gene. Drug Metab Pharmacokinet 24:553-556

86. Mackey JR, Mani RS, Selner M, Mowles D, Young JD, Belt JA, Crawford CR, Cass CE (1998) Functional nucleoside transporters are required for gemcitabine influx and manifestation of toxicity in cancer cell lines. Cancer Res 58:4349-4357

87. Giovannetti E, Del Tacca M, Mey V, Funel N, Nannizzi S, Ricci S, Orlandini C, Boggi U, Campani D, Del Chiaro M, Iannopollo M, Bevilacqua G, Mosca F, Danesi R (2006) Transcription analysis of human equilibrative nucleoside transporter-1 predicts survival in pancreas cancer patients treated with gemcitabine. Cancer Res 66:3928-3935

88. Farrell JJ, Elsaleh H, Garcia M, Lai R, Ammar A, Regine WF, Abrams R, Benson AB, Macdonald J, Cass CE, Dicker AP, Mackey JR (2009) Human equilibrative nucleoside transporter 1 levels predict response to gemcitabine in patients with pancreatic cancer. Gastroenterology 136:187-195. doi:10.1053/j. gastro.2008.09.067

89. Maréchal R, Mackey JR, Lai R, Demetter P, Peeters M, Polus M, Cass CE, Young J, Salmon I, Devière J, Van Laethem JL (2009) Human equilibrative nucleoside transporter 1 and human concentrative nucleoside transporter 3 predict survival after adjuvant gemcitabine therapy in resected pancreatic adenocarcinoma. Clin Cancer Res 15:2913-2919

90. Sebastiani V, Ricci F, Rubio-Viqueira B, Kulesza P, Yeo CJ, Hidalgo M, Klein A, Laheru D, Iacobuzio-Donahue CA (2006) Immunohistochemical and genetic evaluation of deoxycytidine kinase in pancreatic cancer: relationship to molecular mechanisms of gemcitabine resistance and survival. Clin Cancer Res 12:2492-2497

91. Bepler G, Kusmartseva I, Sharma S, Gautam A, Cantor A, Sharma A, Simon G (2006) RRM1 modulated in vitro and in vivo efficacy of gemcitabine and platinum in non-small-cell lung cancer. J Clin Oncol 24:4731-4737

92. Wong A, Soo RA, Yong WP, Innocenti F (2009) Clinical pharmacology and pharmacogenetics of gemcitabine. Drug Metab Rev 41(2):77-88. doi:10.1080/03602530902741828

93. Li L, Fridley B, Kalari K, Jenkins G, Batzler A, Safgren S, Hildebrandt M, Ames M, Schaid D, Wang L (2008) Gemcitabine and cytosine arabinoside cytotoxicity: association with 
lymphoblastoid cell expression. Cancer Res 68:7050-7058. doi:10.1158/0008-5472.CAN-08-0405

94. Xu M, Li L, Liu Z, Jiao Z, Xu P, Kong X, Huang H, Zhang Y (2013) ABCB2 (TAP1) as the downstream target of SHH signaling enhances pancreatic ductal adenocarcinoma drug resistance. Cancer Lett 333:152-158

95. Olive KP, Jacobetz MA, Davidson CJ, Gopinathan A, McIntyre D, Honess D, Madhu B, Goldgraben MA, Caldwell ME, Allard D, Frese KK, Denicola G, Feig C, Combs C, Winter SP, IrelandZecchini H, Reichelt S, Howat WJ, Chang A, Dhara M, Wang L, Rückert F, Grützmann R, Pilarsky C, Izeradjene K, Hingorani SR, Huang P, Davies SE, Plunkett W, Egorin M, Hruban RH, Whitebread N, McGovern K, Adams J, Iacobuzio-Donahue C, Griffiths J, Tuveson DA (2009) Inhibition of Hedgehog signaling enhances delivery of chemotherapy in a mouse model of pancreatic cancer. Science 324:1457-1461

96. Minchinton AI, Tannock IF (2006) Drug penetration in solid tumours. Nat Rev Cancer 6:583-592

97. Tredan O, Galmarini CM, Patel K, Tannock IF (2007) Drug resistance and the solid tumor microenvironment. J Natl Cancer Inst 99:1441-1454

98. Adema AD, Smid K, Losekoot N, Honeywell RJ, Verheul HM, Myhren F, Sandvold ML, Peters GJ (2012) Metabolism and accumulation of the lipophilic deoxynucleoside analogs elacytarabine and CP-4126. Invest New Drugs 30:1908-1916. doi:10.1007/s10637-011-9756-8

99. Poplin E, Wasan H, Rolfe L, Raponi M, Ikdahl T, Bondarenko I, Davidenko I, Bondar V, Garin A, Boeck S, Ormanns S, Heinemann V, Bassi C, Evans TR, Andersson R, Hahn H, Picozzi V, Dicker A, Mann E, Voong C, Kaur P, Isaacson J, Allen A (2013) Randomized, multicenter, phase II study of CO-101 versus gemcitabine in patients with metastatic pancreatic ductal adenocarcinoma: including a prospective evaluation of the role of hENT1 in gemcitabine or CO-101 sensitivity. J Clin Oncol 31:4453-4461

100. Yamamoto N, Nokihara H, Yamada Y, Uenaka K, Sekiguchi R, Makiuchi T, Slapak CA, Benhadji KA, Tamura T (2013) Phase I study of oral gemcitabine prodrug (LY2334737) in Japanese patients with advanced solid tumors. Cancer Chemother Pharmacol 71:1645-1655

101. Faivre SJ, Olszanski AJ, Weigang-Köhler K, Riess H, Cohen RB, Wang X, Myrand SP, Wickremsinhe ER, Horn CL, Ouyang H, Callies S, Benhadji KA, Raymond E (2015) Phase I dose escalation and pharmacokinetic evaluation of two different schedules of LY2334737, an oral gemcitabine prodrug, in patients with advanced solid tumors. Invest New Drugs 33:1206-1216

102. Slusarczyk M, Lopez MH, Balzarini J, Mason M, Jiang WG, Blagden S, Thompson E, Ghazaly E, McGuigan C (2014) Application of ProTide technology to gemcitabine: a successful approach to overcome the key cancer resistance mechanisms leads to a new agent (NUC-1031) in clinical development. J Med Chem 57:1531-1542
103. Ghazaly EA, Joel S, Gribben JG, Mohammad T, Emiloju O, Stavraka C, Hopkins T, Gabra H, Wasan H, Habib NA, Leonard RCF, McGuigan C, Slusarczyk M, Blagden SP (2013) ProGem1: Phase I first-in-human study of the novel nucleotide NUC-1031 in adult patients with advanced solid tumors. J Clin Oncol 31 suppl:abstr 2576

104. Blagden SP, Rizzuto I, Stavraka C, O'Shea D, Suppiah P, Patel M, Loyse N, Sukumaran A, Bharwani N, Rockall A, Gabra H, El-Bahrawy M, Wasan HS, Leonard RCF, Habib NG, McGuigan C, Gribben JG, Ghazaly EA (2015) A first in human Phase I/II study of NUC-1031 in patients with advanced gynecological cancers. J Clin Oncol 33 suppl:abstr. 2547

105. Adema AD, Bijnsdorp IV, Sandvold ML, Verheul HM, Peters GJ (2009) Innovations and opportunities to improve conventional (deoxy)nucleoside and fluoropyrimidine analogs in cancer. Curr Med Chem 16:4632-4643

106. Patra CR, Bhattacharya R, Wang E, Katarya A, Lau JS, Dutta S, Muders M, Wang S, Buhrow SA, Safgren SL, Yaszemski MJ, Reid JM, Ames MM, Mukherjee P, Mukhopadhyay D (2008) Targeted delivery of gemcitabine to pancreatic adenocarcinoma using cetuximab as a targeting agent. Cancer Res 68:1970-1978

107. Reddy LH, Khoury H, Paci A, Deroussent A, Ferreira H, Dubernet C, Decleves X, Besnard M, Chacun H, Lepetre-Mouelhi S, Desmaele D, Rousseau B, Laugier C, Cintrat JC, Vassal G, Couvreur P (2008) Squalenoylation favorably modifies the in vivo pharmacokinetics and biodistribution of gemcitabine in mice. Drug Metab Dispos 36:1570-1577

108. Pasut G, Canal F, Dalla VL, Arpicco S, Veronese FM, Schiavon O (2008) Antitumoral activity of PEG-gemcitabine prodrugs targeted by folic acid. J Control Release 127:239-248

109. Celia C, Malara N, Terracciano R, Cosco D, Paolino D, Fresta M, Savino R (2008) Liposomal delivery improves the growthinhibitory and apoptotic activity of low doses of gemcitabine in multiple myeloma cancer cells. Nanomedicine 4:155-166

110. Joerger M, Burgers JA, Baas P, Doodeman VD, Smits PH, Jansen RS, Vainchtein LD, Rosing H, Huitema AD, Beijnen JH, Schellens JH (2012) Gene polymorphisms, pharmacokinetics, and hematological toxicity in advanced non-small-cell lung cancer patients receiving cisplatin/gemcitabine. Cancer Chemother Pharmacol 69:25-33. doi:10.1007/s00280-011-1670-4

111. Peters GJ, Honeywell RJ, Maulandi M, Giovannetti E, Losekoot N, Etienne-Grimaldi MC, Milano G, Serdjebi C, Ciccolini J, EORTCPharmacology and Molecular Mechanism Group (2014) Selection of the best blood compartment to measure cytidine deaminase activity to stratify for optimal gemcitabine or cytarabine treatment. Nucleosides Nucleotides Nucleic Acids 33:403-412

112. Ueno H, Kiyosawa K, Kaniwa N (2007) Pharmacogenomics of gemcitabine: can genetic studies lead to tailor-made therapy? $\mathrm{Br}$ J Cancer 97:145-151. doi:10.1038/sj.bjc.6603860

113. Okazaki T, Javle M, Tanaka M, Abbruzzese JL, Li D (2010) Single nucleotide polymorphisms of gemcitabine metabolic genes and pancreatic cancer survival and drug toxicity. Clin Cancer Res 16:320-329 